\title{
Missed appointment in rabies vaccination schedule
}

\author{
Esquema de vacinação antirrábica: não comparecimento
}

\section{Viroj Wiwanitkit}

Visiting university professor, Hainan Medical University, China.

Correspondence: Viroj Wiwanitkit; 38/167 Soi Yim Prayoon, Sukbapibarn 1 Road Bangkhae, Bangkok-Thailand, 10160; E-mail:wviroj@yahoo.com

Received 16 May 2012; Received in final form 28 May 2012; Accepted 05 June 2012

Dear Editors,

Rabies is an important fatal neurological infection. The infection is due to the animal bite, especially dog bite. There is no specific treatment. It is suggested that vaccination is the best method for prevention rabies in the patients getting animal bite. Generally, the rabies vaccine is given in divided dosage and there must be the strict date for getting vaccine in vaccine schedule. In Thailand, the tropical country, dog bite is a common problem and the use of rabies vaccination is common. In clinical practice, the concern is on the missed appointment in rabies vaccination schedule $\left(0,3,7,14\right.$ and $28^{\text {th }}$ date). Here, the author reports experience on this specific issue in a primary care center. During 1 month period of observation (March 2012), there are 125 rabies vaccination requests. Of these requests, the missed appointment can be seen in 25 cases (20\%). There are 24 delayed request and 1 precoccious request. The problems are seen in $3^{\text {rd }}$ appointment $\left(7^{\text {th }}\right.$ date) for 2 cases, $4^{\text {th }}$ appointment $\left(14^{\text {th }}\right.$ date $)$ for 8 cases, and $5^{\text {th }}$ appointment ( $28^{\text {th }}$ date) for 15 cases. The given reasons for the cases with delayed requests are forgetting (22 cases), lack of the time for visiting (2 cases), and loss of appointment care (1 case). For the one case with precocious request, the reason is planning to go traveling at the appointment date. Based on this report, it can be seen that the problem of missed appointment in rabies vaccination schedule is very common and this may be the problem in prevention of rabies. The rate of missed appointment in this report is extremely high. In a previous report from another Southeast Asian country with less problem of dog bite, the Philippines, the rate is about $8 \%^{1}$. It seems that post exposure rabies vaccination is usually overlooked by Thai patients. Indeed, the similar problem in vaccination for pets is also observed in Thailand ${ }^{2}$. Hence, the problem of rabies control by vaccination is still existed in Thailand. How to manage the good compliance in getting rabies vaccination according to the vaccine schedule is the topic for further researching.

\section{References}

1. Quiambao BP, DyTioco HZ, Dizon RM, Crisostomo ME, Laot TH, Dirk E. Rabies post-exposure prophylaxis in the Philippines: health status of patients having received purified equine $F\left(a b^{\prime}\right) 2$ fragment rabies immunoglobulin (Favirab). PLoS Negl Trop Dis 2008; 2:e243.
Wasi C, Chaiprasithikul P, Thongcharoen P, Choomkasien P, Sirikawin S. Progress and achievement of rabies control in Thailand. Vaccine 1997;15(Suppl):S7-S11. 